\title{
Validation of QUALAS-T, a health-related quality of life instrument for teenagers with spina bifida
}

\author{
Konrad M. Szymański, Rosalia Misseri, Benjamin Whittam, Jessica T. Casey, David Y. Yang,
} Sonia-Maria Raposo, Shelly J. King, Martin Kaefer, Richard C. Rink, Mark P. Cain

Division of Pediatric Urology, Riley Hospital for Children, Indiana University School of Medicine, Indianapolis, Indiana, USA

Citation: Szymański KM, Misseri R, Whittam B, et al. Validation of QUALAS-T, a health-related quality of life instrument for teenagers with spina bifida. Cent European J Urol. 2017; 70: 306-313.

Article history

Submitted: Dec. 12, 2016

Accepted: May 28, 2017

Published online: Jun. 23, 2017
Corresponding author Konrad M. Szymański Indiana University School of Medicine

Riley Hospital for Children Division of Pediatric Urology Indianapolis, IN 46202, USA 705 Riley Hospital Dr., ROC4230

szymanko@iupui.edu
Introduction We aimed to develop and validate a self-reported QUAlity of Life Assessment in Spina bifida for Teenagers (QUALAS-T).

Material and methods We drafted a 46-question pilot instrument using a patient-centered comprehensive item generation/refinement process. A group of 13-17 years olds with spina bifida (SB) was recruited online via social media and in person at SB clinics (2013-2015). Healthy controls were recruited during routine pediatrician visits. Final questions were identified based on clinical relevance, factor analysis and domain psychometrics. Teenagers with SB completed the validated generic Kidscreen-27 instrument. Results Median age of 159 participants was 15.2 years (42.0\% male, $77.4 \%$ Caucasian), similar to 58 controls $(p \geq 0.06)$. There were 102 online and 57 clinic participants ( $82.8 \%$ of eligible). Patients, parents and an expert panel established face and content validity of the 2-domain, 10-question QUALAS-T. Internal consistency and test-retest reliability were high for the Family and Independence and Bladder and Bowel domains (Cronbach's alpha: 0.76-0.78, ICC: 0.72-0.75). The Bladder and Bowel domain is the same for QUALAS-T, QUALAS-A for adults and QUALAS-C for children. Correlations between QUALAS-T domains were low $(r=0.34)$, indicating QUALAS-T can differentiate between distinct HRQOL components. Correlations between QUALAS-T and Kidscreen-27 were also low $(r \leq 0.41)$. QUALAS-T scores were lower in teenagers with SB than without ( $p<0.0001)$.

Conclusions QUALAS-T is a short, valid HRQOL tool for adolescents with SB, applicable in clinical and research settings. Since the Bladder \& Bowel domains for all QUALAS versions are the same, Bladder and Bowel HRQOL can be measured on the same scale from age 8 through adulthood.

Key Words: child « fecal incontinence « meningomyelocele « quality of life () spinal dysraphism «) urinary incontinence

\section{INTRODUCTION}

Spina bifida (SB) is a common congenital anomaly of the central nervous system, affecting multiple organ systems, including bladder and bowel function [1]. One of the goals of SB management is optimizing SB-specific health-related quality of life (HRQOL), or the individual's perception of the impact of SB on his or her physical and psychosocial functioning $[2,3]$. This is particularly important in teenagers with SB as they transition to more independent adult care. One of the challenges to this approach is that no clinically useful and validated tools exist for this age group, especially ones that incorporate bladder and bowel domains [4]. Several small, singleinstitutional studies published to date used limited and poorly validated or non-validated instruments. [4-10] Generic HRQOL instruments validated for healthy teenagers[11-14] were not developed to capture the impact of SB on HRQOL or to detect clinically meaningful differences in HRQOL [2].

A clinically relevant HRQOL instrument focuses on HRQOL specific to SB, and not physical function, is short and has excellent psychometric properties [2, 4]. 
It should be developed with input from multiple stakeholders: teenagers, their parents, caregivers and healthcare providers, and should accommodate teenagers' cognitive and emotional development [2, 4]. Our goal was to develop and validate a clinically useful, self-reported, disease-specific, health-related QUAlity of Life Assessment in Spina bifida for Teenagers (QUALAS-T).

\section{MATERIAL AND METHODS}

The study protocol received Internal Review Board approval (IRB 9470) and followed the patient-reported outcome instrument development guidelines from the Federal Drug Administration [15]. The study protocol was similar to that used to develop and validate QUALAS versions for adults (QUALAS-A) [16] and children (QUALAS-C) [17].

\section{Eligibility and exclusion criteria}

Adolescents (13-17 years old) with a history of myelomeniongocele or lipomeningocele requiring newborn spine surgery were recruited either online via social media, or in person at outpatient multidisciplinary SB clinics. A questionnaire was administered between January 2013 and August 2015. Non-eligibility criteria included: a primary diagnosis other than spina bifida (primary tethered cord, sacral agenesis, medullary lipoma, anorectal malformation, spinal trauma, tumor), poor self-reported English proficiency, developmental delay interfering with comprehension of questions, or surgery in the last month. Eligible participants were excluded if they did not complete the questionnaire. Eligibility and exclusion criteria remained unchanged for all phases of this study. Healthy controls without SB were recruited at two local pediatrics clinics during routine checkup visits.

\section{Phase 1. Item generation}

QUALAS-T was developed using a comprehensive, patient-centered item generation and refinement process (Figure 1). Items (questions) were generated from a series of 10 semi-structured interviews with teenagers with SB and their families, a review of published instruments as well as the opinions of 20 national and international experts in SB care (see Acknowledgments). The item generation process was stopped when no new items were generated, yielding a comprehensive list of 147 items covering themes of cognition, independence, emotional impact, social interactions, romantic concerns, educational, work and leisure activities, mobility, health-
Phase 1: Item generation (147 items)

- Semi-structured interviews with 10 patients with SB and families

- Review of published instruments

- Expert opinion

Phase 2: Development of pilot instrument (46 items)

- Items reworded and selected based on importance ranking by 10 patients with SB and families and expert opinion

Phase 3: Participant recruitment

- 58 controls without SB recruited

- 156 teenagers with SB recruited

Phase 4: Refinement of instrument

- Review by SB expert panel

- Removal of insensitive items

- Factor analysis

Phase 5: Validation of instrument

- Validity: face, content, convergent and discriminant

- Reliability: internal consistency and test-retest

Final QUALAS-T instrument (10 items)

- A valid and reliable assessment of HRQOL in teens with SB

Figure 1. Creation of the QUAlity of Life Assessment in Spina bifida in Teenagers (QUALAS-T). SB - Spina Bifida.

care interactions, toileting, as well as urinary and fecal continence. This exhaustive list was reduced to 90 items by an expert panel, which eliminated similarly worded and redundant items, while maintaining the themes.

\section{Phase 2. Development of pilot instrument}

The 90 items were rated on importance by 6 teenagers with SB and 6 parents from our center's SB clinic. Ratings were made on a 3-point Likert scale (not important, somewhat important, very important). After review by an expert panel, 46 items with the highest rankings per theme were selected to create a more manageable and representative pilot QUALAS-T. This item reduction approach has been successfully used in other studies in the SB population $[8,9,18]$. Some items were reworded to ensure comprehension and clarity based on feedback from the 12 individuals rating the questions and a Health 
Literacy Educator at our institution's Family Education Center (see Acknowledgments). Readability was assessed by the Flesch Kincaid Grade Level test [19]. The pilot QUALAS-T was self-administered. Questions were close-ended and numbered to avoid omission. Similar to several other pediatric instruments, questions reflected the last 4 weeks [9, 12, 20]. Responses used a 5-point Likert scale (never, almost never, sometimes, almost always, always), an approach successfully used in other instruments $[8,9,11,12,20]$. Items focusing on similar themes were grouped together to simulate the final QUALAS-T instrument.

\section{Phase 3. Further participant recruitment}

A demographic questionnaire and the pilot QUALAS-T were administered anonymously to a sample of teenagers with SB and controls in a cross-sectional survey. Teenagers with SB also completed the validated general Kidscreen-27 instrument [11]. In order to open the study to teenagers from a variety of social and healthcare setting, participants were recruited through local and national organizations via social media (see Acknowledgments) and at an outpatient multidisciplinary SB clinics. Consent was obtained online (computer-based) or in person (clinic-based). Two-week test-retest reliability was assessed by readministering the QUALAS-T to participants recruited in clinic. Teenagers with SB and controls received $\$ 5$ incentive payments. Incentive payments were increased to $\$ 25$ in the final 6 months of the study to encourage enrollment.

\section{Phase 4. Refinement of instrument}

A factor analysis on 46 items would require at approximately 230 participants (5 participants/item) for adequate statistical power [21, 22]. The study was closed after 32 months of recruitment despite not reaching 230 participants. To further refine the instrument, we performed a principal axes method of factor analysis using varimax (orthogonal) rotation [23, 24]. The number of extracted factors/domains was based on five criteria described previously: scree plot inflexion point, multiple models with different numbers of factors and 5 rotations, extracted factors having $\geq 3$ variables with loadings $\geq 0.4$, clinical plausibility/ relevance, and statistical properties of each domain [16, 23, 24]. Based on these criteria, the final QUALAS-T instrument consisted of two domains of 5 items each. QUALAS-T is scored $0-100$, where higher values signify higher HRQOL, and takes less than 5 minutes to complete. In the event only four responses are provided for a 5-item domain, we suggest considering these four items in the domain [25].

\section{Phase 5. Internal validation}

We assessed different types of validity to ensure that the 10-item QUALAS-T measures what it intends to measure [26]. A review by patients, families and experts established face and content validity of QUALAS-T. Factor analysis additionally assessed construct validity. For each domain score, we calculated the mean, standard deviation (SD), median, range and the percentage of participants scoring minimum (floor) and maximum (ceiling) values. Reliability, or reproducibility, was assessed using internal consistency (Cronbach's alpha: 0.7-0.9 signifying good consistency without redundancy) [26] and two-week test-retest reliability (Intraclass Correlation Coefficient, ICC: $\geq 0.7$ indicating acceptable reliability) [27].

Conceptual independence or redundancy of QUALAS-T domains was assessed with convergent and divergent validity. Convergent validity evaluates the degree to which QUALAS-T scores converge with other instruments measuring similar outcomes. On the other hand, divergent validity evaluates the degree to which QUALAS-T scores diverge from those measured by dissimilar instruments. We calculated Pearson correlation coefficients (r) among QUALAS-T domains and with Kidscreen-27 domains. To further assess divergent validity, domain scores between the teenagers with SB and controls were compared using a t-test. To quantify effect size, we used a previously established method of dividing the mean difference between teenagers with SB and controls by the SD of the control population [28, 29]. Several distribution-based approaches were used to determine what minimally important difference could be considered clinically significant. Estimated point differences were determined using 1/2 SD, [30] internal consistency and test-retest reliability, as previously described [31, 32]. For each domain, we selected the most conservative, largest point difference calculated by the three methods as the minimal important score difference. A critical $\mathrm{p}=0.05$ was used (v9.4, SAS Institute, Cary, NC).

\section{RESULTS}

\section{Phases 1 and 2. Development of pilot instrument}

The 46-item pilot instrument was developed in a multifaceted, patient-centered fashion (Figure 1). Ten semi-structured interviews lasted a mean of 20 minutes. 


\section{Phase 3. Demographics}

Of 110 clinic patients screened, $68(61.8 \%)$ met eligibility criteria, and $57(83.8 \%)$ were ultimately enrolled (Figure 2). Of 124 online participants, $124(100.0 \%)$ met eligibility criteria, and $102(82.3 \%)$ were enrolled. We noted no significant differences in gender or age between eligible teenagers who were and were not enrolled.

Median age of 159 participants was 15.2 years (42.0\% male, $77.4 \%$ Caucasian), similar to 58 controls ( $\mathrm{p} \geq 0.06$ ) (Table 1). Half of participants were community ambulators (55.0\%) and $71.7 \%$ had a ventriculoperitoneal shunt. Most participants performed clean intermittent catheterizations (77.4\%) and $78.6 \%$ reported daytime urinary dry intervals of at least $4 \mathrm{~h}$. Participants lived in 30 states of the United States, encompassing $83 \%$ of the country's population in 2011 [33].

\section{Phase 4. Factor Analysis}

A break in the scree plot slopes on unrotated and varimax rotated factor analyses of 46 items suggested two meaningful factors, followed by a decreas- ing slope of minor factors (Table 1). Similar findings were obtained on the other 5 rotations. These two factors (Family and Independence, Bladder and Bowel) accounted for $46.9 \%$ of the total variance.

\section{Phase 5. Internal validation}

A review by patients, families and experts established content and face validity of the final 10-question QUALAS-T. The Flesch Kincaid Grade Level test indicated a fifth grade reading level. Properties of the QUALAS-T domain scores were calculated, without evidence of floor or ceiling effects (Table 2). Each of the two domains had robust internal consistency (Cronbach's alpha: $0.76-0.78$ ) and test-retest validity (ICC: $0.72-0.75$ ). The mean two-week test-retest changes were small for each domain $(+1.9$ to +4.3$)$. Missing data was acceptably low for each domain (Family and Independence: $6.9 \%$, Bladder and Bowel: 0.6\%).

Correlations between QUALAS-T domains were low $(r=0.34)$, indicating that QUALAS-T differentiates between two distinct HRQOL components (Table 3). Correlations between QUALAS-T and Kidscreen-27 domains were also low ( $\mathrm{r} \leq 0.41$ ), supporting the concurrent use of these instruments.

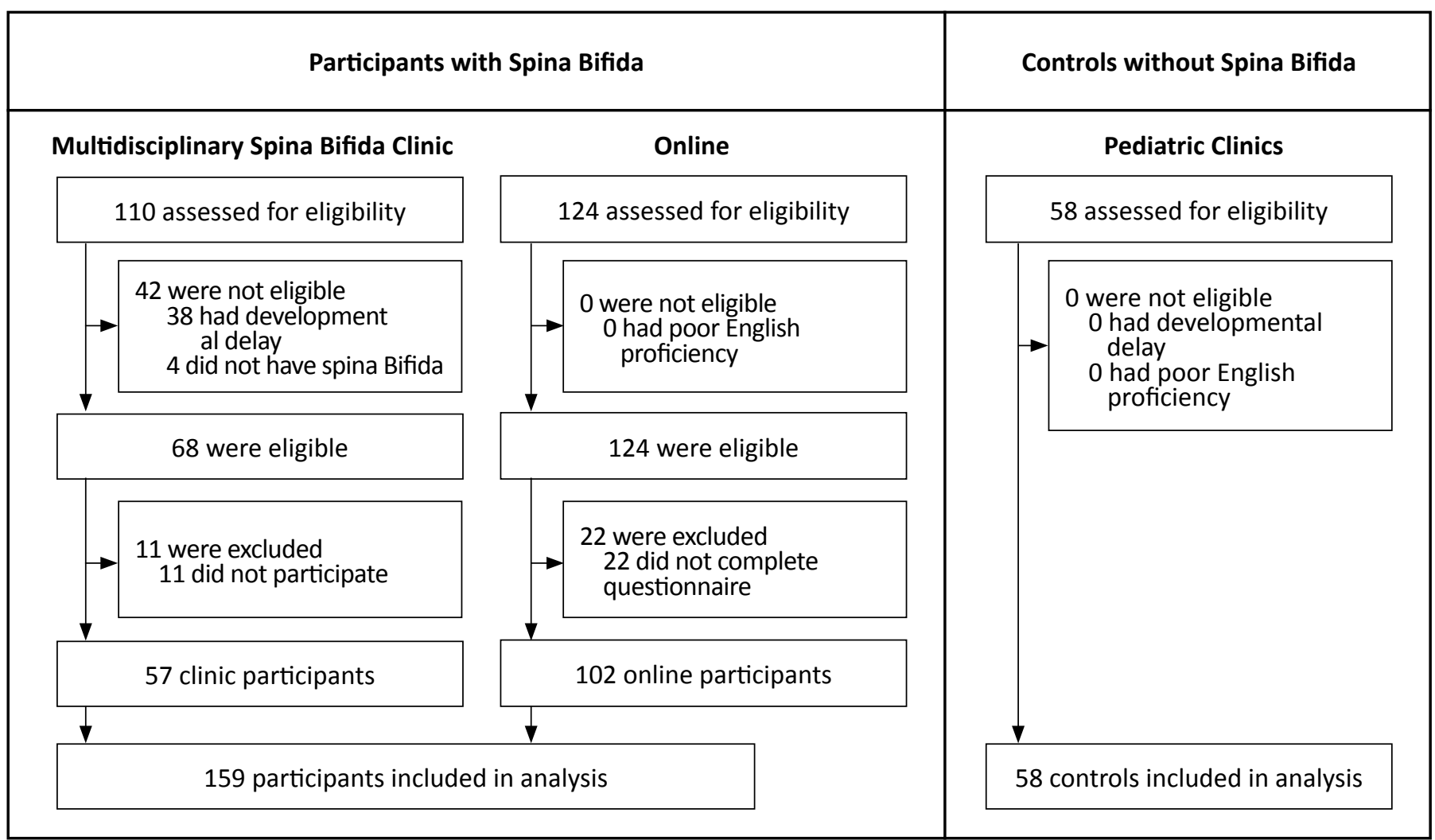

Figure 2. Enrollment of teenagers into the study Teenagers were enrolled at an outpatient multidisciplinary spina bifida as well as online via social media. Enrollment commenced in January 2013 through August 2015 (32 months). Healthy controls without SB were recruited from two local pediatrics clinics during routine checkup visits. 
QUALAS-T scores for controls were significantly higher than teenagers with SB for both domains $(\mathrm{p}<0.0001)$, each with a large effect size $(\geq 1.0)$ (Table 2). Similar to teenagers with SB, missing data was low for each domain (Family and Independence: 5.2\%, Bladder and Bowel: 0.0\%). Using several distribution-based approaches, we calculated the minimally important difference to be $\geq 15$ for both domains (range: 11.7-13.4).

\section{DISCUSSION}

We present a novel, validated HRQOL instrument developed specifically for teenagers with SB. QUALAS-T

Table 1. Factor analysis of responses from 159 teenagers with spina bifida

\begin{tabular}{lcc}
\hline Item & Factor 1 & Factor 2 \\
\hline Having future children & $63^{*}$ & 6 \\
\hline Finding a partner & $60^{*}$ & 9 \\
\hline Bother by others helping & $59^{*}$ & -1 \\
\hline Bother by family helping & $59^{*}$ & -5 \\
\hline Doing what others can do & $54^{*}$ & 26 \\
\hline Bowel wait bother & 14 & $64^{*}$ \\
\hline Worry about pads being noticed & 26 & $62^{*}$ \\
\hline Bowel leak bother & 7 & $61^{*}$ \\
\hline Urine problems stop you from fun things & 37 & $51^{*}$ \\
\hline Urine leak bother & 37 & $40^{*}$ \\
\hline
\end{tabular}

*Factor loading value is greater than the geometric mean (root mean square) of all values in the matrix.

A similar analysis was performed on 36 other items assessed (data not shown). Each row represents an item scale coded on a scale of $1=$ never to $5=$ always. Factor loadings in the table are multiplied by 100 and rounded to the nearest integer. is composed of items relevant to teenagers with $\mathrm{SB}$, their families and clinicians, including items relating to intimate relationships and a comprehensive domain focusing on bladder and bowel dysfunction. Rather than treating QUALAS-T scores as absolutes, scores may be best compared longitudinally to the same person over time, or between individuals.

QUALAS-T is the third and final of a set of short, age-specific HRQOL instruments meant to be selfadministered by people with SB. Both QUALAS-C (Children: 8-12 years old) and QUALAS-T have two domains of 5 items each [17]. QUALAS-A (Adults: $\geq 18$ ) has three domains of 5 items each[16]. All three questionnaires contain unique age-specific items addressing issues relating to esteem and independence, with QUALAS-A also containing items on sexuality and relationships (Table 4). All three QUALAS questionnaires share the same Bladder and Bowel domain, allowing Bladder and Bowel HRQOL to be tracked with the same questions starting at 8 years old. Low rates of missing data for all QUALAS instruments suggest they are not difficult to complete. Finally, for each QUALAS domain, we have established minimally important differences between two scores to reflect clinically significant differences.

Over the last 20 years, three other SB-specific HRQOL instruments have been developed [8, 9, 10]. Among these, only the Parkin et al. instrument has a patient-reported version for teenagers 13-18 years old [8]. Similar to the other two other instruments, the questionnaire by Parkin et al. is lengthy (47 items) and does not comprehensively address bladder and bowel care. Finally, it is unclear what score change, or difference, on any of these instruments can be considered clinically relevant.

Table 2. Domain characteristics of the self-reported QUALAS-T in adolescents with and without spina bifida

\begin{tabular}{|c|c|c|c|c|c|c|c|c|}
\hline \multicolumn{9}{|c|}{ Adolescents with spina bifida } \\
\hline Domain & $\mathrm{N}$ & $\%$ missing & Mean (SD) & Median (Range) & $\begin{array}{l}\text { \% Scoring } \\
\text { Minimum }\end{array}$ & $\begin{array}{l}\text { \% Scoring } \\
\text { Maximum }\end{array}$ & $\begin{array}{l}\text { Cronbach's } \\
\text { alpha }\end{array}$ & $\begin{array}{l}\text { Test-retest } \\
\text { reliability (ICC) }\end{array}$ \\
\hline $\begin{array}{l}\text { Family and } \\
\text { Independence }\end{array}$ & 148 & 6.9 & $57.0(23.5)$ & $60.0(0.0-100.0)$ & 2.0 & 4.1 & 0.76 & 0.75 \\
\hline Bladder and Bowel & 158 & 0.6 & $68.5(25.3)$ & $70.0(5.0-100.0)$ & 0.0 & 15.8 & 0.78 & 0.72 \\
\hline \multicolumn{9}{|c|}{ Adolescents without spina bifida } \\
\hline Domain & $\mathrm{N}$ & $\%$ missing & Mean (SD) & Median (Range) & $\begin{array}{l}\text { \% Scoring } \\
\text { Minimum }\end{array}$ & $\begin{array}{l}\text { \% Scoring } \\
\text { Maximum }\end{array}$ & $\begin{array}{l}\text { Mean difference } \\
\text { for adolescents } \\
\text { with SB* } \\
(p-v a l u e)\end{array}$ & $\begin{array}{l}\text { Effect size vs. } \\
\text { adolescents with } \\
\text { spina bifida** }\end{array}$ \\
\hline $\begin{array}{l}\text { Family and } \\
\text { Independence }\end{array}$ & 55 & 5.2 & $86.1(18.8)$ & $95.0(20.0-100.0)$ & 0.0 & 36.4 & $-29.4(<0.0001)$ & $\begin{array}{c}-1.6 \\
\text { Large (-) }\end{array}$ \\
\hline Bladder and Bowel & 58 & 0.0 & $96.7(12.0)$ & $100.0(20.0-100.0)$ & 0.0 & 87.9 & $-28.3(<0.0001)$ & $\begin{array}{c}-2.4 \\
\text { Large (-) }\end{array}$ \\
\hline
\end{tabular}

Abbreviations: QUALAS-T: QUAlity of Life Assessment in Spina bifida for Teenagers; SD: Standard Deviation; ICC: Intraclass Correlation Coefficient. ${ }^{*}$ t-test. ${ }^{* *}$ Effect size was calculated as difference in means (spina bifida-no spina bifida) divided by the standard deviation of group without spina bifida (0.2: small, 0.5: moderate, 0.8: large effect) 
CEntral European Journal of UROLOGY

Table 3. Interscale correlations between QUALAS-T domains and the Kidscreen-27 summary scores

\begin{tabular}{|c|c|c|c|c|c|c|c|c|}
\hline \multirow[t]{2}{*}{ Instrument } & \multirow[t]{2}{*}{ Domain } & \multicolumn{2}{|c|}{ QUALAS-T } & \multicolumn{5}{|c|}{ Kidscreen-27 } \\
\hline & & $\begin{array}{c}\text { Family and } \\
\text { Independence }\end{array}$ & $\begin{array}{c}\text { Bladder and } \\
\text { Bowel }\end{array}$ & $\begin{array}{l}\text { Physical } \\
\text { Well-being }\end{array}$ & $\begin{array}{l}\text { Psychological- } \\
\text { Well-being }\end{array}$ & $\begin{array}{c}\text { Autonomy } \\
\text { and Parent } \\
\text { Relation }\end{array}$ & $\begin{array}{c}\text { Social } \\
\text { Support } \\
\text { and Peers }\end{array}$ & $\begin{array}{c}\text { School } \\
\text { Environment }\end{array}$ \\
\hline \multirow{2}{*}{ 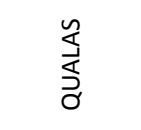 } & $\begin{array}{l}\text { Family and } \\
\text { Independence }\end{array}$ & 1.00 & - & - & - & - & - & - \\
\hline & Bladder and Bowel & 0.34 & 1.00 & - & - & - & - & - \\
\hline \multirow{5}{*}{ 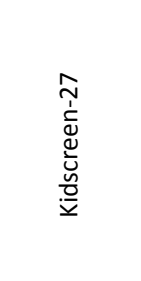 } & Physical Well-being & $0.16^{d}$ & $0.21^{c}$ & 1.00 & - & - & - & - \\
\hline & Psychological Well-being & 0.41 & $0.28^{b}$ & 0.37 & 1.00 & - & - & - \\
\hline & $\begin{array}{l}\text { Autonomy and } \\
\text { Parent Relation }\end{array}$ & $0.23^{c}$ & $0.31^{\mathrm{a}}$ & $0.31^{a}$ & 0.47 & 1.00 & - & - \\
\hline & Social Support and Peers & $0.13^{\mathrm{d}}$ & $0.12^{\mathrm{d}}$ & $0.32^{\mathrm{a}}$ & 0.46 & 0.38 & 1.00 & - \\
\hline & School Environment & $0.24^{c}$ & $0.11^{\mathrm{d}}$ & 0.37 & 0.42 & 0.49 & $0.34^{a}$ & 1.00 \\
\hline
\end{tabular}

QUALAS-T - QUAlity of Life Assessment in Spina bifida for Teenagers

$p<0.0001$ for all correlations, except where marked: ${ }^{a} p \leq 0.001,{ }^{b} p \leq 0.01,{ }^{c} p \leq 0.05,{ }^{d} p \geq 0.10$

Table 4. Comparison of the three QUALAS questionnaires

\begin{tabular}{|c|c|c|c|}
\hline Item & QUALAS-C 2.0 (8-12 years old) & QUALAS-T (13-17 years old) & QUALAS-A (18 years old and older) \\
\hline Domain & Esteem and Independence* & Family and Independence & Esteem and Sexuality \\
\hline Embarrassment about your look & $x$ & & $x$ \\
\hline Dealing with health problems & $x$ & & \\
\hline Urine catheterization bother & $x$ & & \\
\hline Bother by family helping & $x$ & $x$ & \\
\hline Bother by others helping & $x$ & $x$ & \\
\hline Doing what others can do & & $x$ & \\
\hline Finding a partner & & $x$ & \\
\hline Treated differently because of health problems & & & $x$ \\
\hline Having future children & & $x$ & $x$ \\
\hline Bother by sexual in/activity & & & $x$ \\
\hline Future sexual satisfaction & & & $x$ \\
\hline Domain & Bladder and Bowel & Bladder and Bowel & Bladder and Bowel \\
\hline Worry about pads being noticed & $x$ & $x$ & $x$ \\
\hline Bother by urine leak & $x$ & $x$ & $x$ \\
\hline Urine problems stop you from fun things & $x$ & $x$ & $x$ \\
\hline Bother by bowel leak & $x$ & $x$ & $x$ \\
\hline Bother by waiting for bowel movement & $x$ & $x$ & $x$ \\
\hline Domain & & & Health and Relationships* \\
\hline Overall health & & & $x$ \\
\hline People saw you for more than health problems & & & $x$ \\
\hline Able to do fun things & & & $x$ \\
\hline Time with friends & & & $x$ \\
\hline Close friendships outside family & & & $x$ \\
\hline
\end{tabular}

* For this domain, the minimally important difference between two scores that represents a clinically significant difference was $\geq 10$. This difference was $\geq 15$ for the remaining domains. 
Another reason for developing QUALAS-T was that generic HRQOL instruments developed for teenagers without SB, such as Kidscreen, [11] fail to capture aspects of HRQOL important to teenagers with SB. As the concept of HRQOL may vary between individuals with and without SB, QUALAS-T scores of 'healthy controls' are therefore likely of no clinical relevance and were used only to calculate validation statistics in this study.

Our study has several limitations. Despite an aggressive recruitment strategy over a prolonged 32-month period, we recruited only $2 / 3$ of the ambitious 230 teenagers planned for a well-powered factor analysis. Nonetheless, this large sample of adolescents with SB is one of the largest in the literature and, we believe, did not impair the statistical analysis, as the results were consistent on all analyses performed. Study participants may have had fewer developmental and functional limitations than the general SB population. In addition, selection bias of eligible participants is unlikely to have played a significant role, as eligible adolescents who were and were not enrolled had similar characteristics. While we did not use anchor-based methods to calculate minimally important differences, distribution- and anchor-based methods have been shown to give comparable results [34]. Finally, since this was validation study, risk factors for lower HRQOL were not investigated.

\section{CONCLUSIONS}

QUALAS-T is a short, validated tool for evaluating HRQOL in adolescents with SB, making it a useful instrument in both clinical and research settings. Since the Bladder and Bowel domains for QUALAS-T and QUALAS-A are the same, this aspect of SBspecific HRQOL can be measured on the same scale after age 13 and into adulthood.

\section{CONFLICTS OF INTEREST}

The authors declare no conflicts of interest.

\section{ACKNOWLEDGMENTS}

We would like to thank the many teenagers with Spina Bifida and their parents and caregivers who participated in this study. We also want to thank the following individuals and groups for their help: Concept and Content Consultant: Kathleen J. Sawin, PhD CPNP-PC FAAN (College of Nursing, University of Wisconsin-Milwaukee Children's Hospital of Wisconsin). Content Consultants: Pediatric Urol- ogy: John Paul Capolicchio, MD (Montreal Children's Hospital, McGill University), Mohamed Elsherbini, MD (Montreal Children's Hospital, McGill University), Walid Farhat, MD (Hospital for Sick Children, University of Toronto), Richard Grady, MD (Seattle Children's Hospital, University of Washington), Roman Jednak, MD (Montreal Children's Hospital, McGill University), David B. Joseph, MD (University of Alabama at Birmingham), Alison C. Keenan, MD (Riley Hospital for Children, Indiana University Health), Martin A. Koyle, MD (Hospital for Sick Children, University of Toronto), Andrew L. MacNeily, MD (British Columbia Children's Hospital, University of British Columbia), JL Pippi Salle, MD (Hospital for Sick Children, University of Toronto), Melissa A. Young, CPNP (Riley Hospital for Children, Indiana University Health). Pediatrics: Timothy J. Brei, MD (Seattle Children's Hospital, University of Washington), Joseph O'Neil, MD (Riley Hospital for Children, Indiana University Health). Clinical Pediatric Psychology: Khush Amaria, PhD (Hospital for Sick Children, University of Toronto). Health Literacy: Cynthia Latty, RN (Riley Hospital for Children, Indiana University Health). Statistics Consultants: Robert Haley, MD (University of Texas Southwestern, Dallas), Patrick Monahan, PhD (Richard M. Fairbanks School of Public Health, Indiana University, Indianapolis). Participant Recruitment: Ahmad H. Bani-Hani, MD, (Alfred I. duPont Hospital for Children, Thomas Jefferson University), Robin Bowman, MD (Lurie Children's Hospital of Chicago, Northwestern University), Timothy J. Brei, MD (Seattle Children's Hospital, Seattle Children's Hospital), David J. Chalmers, MD (Maine Medical Center), Dominic C. Frimberger, MD (The Children's Hospital of Oklahoma, University of Oklahoma), Betsy Hopson, MSHA (Children's Hospital of Alabama, University of Alabama at Birmingham), Jill Mazurek, MD (Indiana University Health), Audrey Rhee, MD (Cleveland Clinic Children's Hospital, Cleveland Clinic Lerner College of Medicine of Case Western Reserve University), Brandon G. Rocque, MD (Children's Hospital of Alabama, University of Alabama at Birmingham), Dorota A. Szczepaniak, MD (Riley Hospital for Children, Indiana University Health), Gino J. Vricella, MD (St Louis Children's Hospital, Washington University), Hadley Wood, MD (Cleveland Clinic, Cleveland Clinic Glickman Urological and Kidney Institute). Record Entry and Review: Sable Amstutz, MD (Indiana University Health), Kyle Hardacker (Indiana University Health), Zoe King (Indiana University Health), Sophie Mazurek (Indiana University Health), Meredith Metcalf, MD (University of Tennessee HealthSciences Centre). Organizations assisting in participant recruitment: International Federation for Spina Bifida and Hydrocephalus and the Spina Bifida Association (United States), as well as: Spina Bifida Associations of Alabama, the Carolinas, Community of Memphis, Connecticut, Georgia, Greater New England, Illinois, Indiana, Kentucky, Nassau County, New Orleans, North Texas, Texas, Washington, Western Pennsylvania, Wisconsin, SB Resource Network, Spina Bifida Connection, National Birth Defects Prevention Network, Disabled Children of Vietnam Veterans. Research support: Funding was provided by the Indiana University School of Medicine's Department of Urology.

\section{References}

1. Liptak GS, Garver K, Dosa NP. Spina bifida grown up. Journal of developmental and behavioral pediatrics: J Dev Behav Pediatr. 2013; 34: 206-215.
2. Waters E, Davis E, Ronen GM, Rosenbaum P, Livingston M, Saigal S. Quality of life 
instrumentsfor children and adolescents with neurodisabilities: how to choose the appropriate instrument. DevMed Child Neurol. 2009; 51: 660-669.

3. Bullinger $M$, Anderson R, Cella $D$, Aaronson N. Developing and evaluating cross-culturalinstruments from minimum requirements to optimal models. Qual Life Res. 1993; 2: 451-459.

4. Sawin KJ, Bellin MH. Quality of life in individuals with spina bifida: a research update. Dev Disabil Res Rev. 2010; 16: 47-59.

5. Vajda P, Kispal Z, Lenart I, Farkas A, Vastyan AM, Pinter AB. Quality of life: urinary bladder augmentation or substitution in children. Pediatr Surg Int. 2009; 25: 195-201.

6. MacNeily AE, Jafari S, Scott H, Dalgetty A, Afshar K. Health related quality of life in patients with spina bifida: a prospective assessment before and after lower urinary tract reconstruction. J Urol. 2009; 4 Suppl 182: 1984-1991.

7. Olesen JD, Kiddoo DA, Metcalfe PD. The association between urinary continence and quality of life in paediatric patients with spina bifida and tethered cord. Paediatr Child Health. 2013; 18: e32-38.

8. Parkin PC, Kirpalani HM, Rosenbaum PL, et al. Development of a health-related quality of life instrument for use in children with spina bifida. Qual Life Res. 1997; 6: 123-132.

9. Kulkarni AV, Rabin D, Drake JM. An instrument to measure the health status in children with hydrocephalus: the Hydrocephalus Outcome Questionnaire. J Neurosurg. 2004; 101: 134-140.

10. Nanigian DK, Nguyen T, Tanaka ST, Cambio A, DiGrande A, Kurzrock EA. Development and validation of the fecal incontinence and constipation quality of life measure in children with spinabifida. J Urol. 2008; 180: 1770-1773.

11. Ravens-Sieberer $U$, Auquier P, Erhart $M$, et al. The KIDSCREEN-27 quality of life measure for children and adolescents: psychometric results from a cross-cultural survey in 13 European countries. Qual Life Res. 2007; 16: 1347-1356.

12. Varni JW, Seid M, Rode CA. The PedsQL: measurement model for the pediatric quality of life inventory. Med Care. 1999; 37: 126-139.
13. Ravens-Sieberer U, Bullinger M. Assessing health-related quality of life in chronically ill children with the German KINDL: first psychometric and content analytical results. Qual Life Res. 1998; 7: 399-407.

14. Landgraf JM AL, Ware JE, Jr. The CHQ. A User's Manual; The Health Institute, New England Medical Center, Boston, MA; 1996.

15. Patrick DL, Burke LB, Powers JH, et al. Patient-reported outcomes to support medical product labeling claims: FDA perspective. Value Health. 2007; 10 Suppl 2: S125-137.

16. Szymanski KM, Misseri R, Whittam B, et al. QUAlity of Life Assessment in Spina bifida for Adults (QUALAS-A): development and international validation of a novel healthrelated quality of life instrument. Qual Life Res. 2015; 24: 2355-2364.

17. Szymanski KM, Misseri R, Whittam B, et al. Quality of Life Assessment in Spina Bifida for Children (QUALAS-C): Development and Validation of a Novel Health-related Quality of Life Instrument. Urology. 2016; 87: 178-184.

18. Sawicki GS, Lukens-Bull K, Yin X, et al. Measuring the transition readiness of youth with special healthcare needs: validation of the TRAQ- Transition Readiness Assessment Questionnaire. J Pediatr Psychol. 2011; 36: 160-171.

19. Kincaid JP, Fishburne LRP, Jr., Rogers RL, Chissom BS. Derivation of new readability formulas (Automated Readability Index, Fog Count and Flesch Reading Ease Formula) for Navy enlisted personnel. Research Branch Report 8-75. 1975: 1-48.

20. Topolski TD, Patrick DL, Edwards TC, Huebner CE, Connell FA, Mount KK. Quality of life and health-risk behaviors among adolescents. J Adolesc Health. 2001; 29: 426-435.

21. Bryant FB, Yarnold PR. Principal components analysis and exploratory and confirmatory factor analysis. In: Grimm LG, Yarnold RR, es. Reading and understanding multivariale statistics. Washington, DC: American Psychological Association; 1995. pp. 99-136.

22. Gorsuch RL. Factor analysis. 2nd ed Hillsdale NJ; L. Erlbaum Associates; 1983.

23. Joliffe IT, Morgan BJ. Principal component analysis and exploratory factor analysis.
Statistical methods in medical research. Stat Methods Med Res. 1992; 1: 69-95.

24. Streiner DL. Figuring out factors: the use and misuse of factor analysis. Can J Psychiatry. 1994;39:135-140.

25. Skevington SM, Lotfy M, O'Connell KA, Group W. The World Health Organization's WHOQOLBREF quality of life assessment: psychometric properties and results of the international field trial. A report from the WHOQOL group. Qual Life Res. 2004; 13: 299-310.

26. Streiner DL, Norman GR. Health measurement scales: a practical guide to their development and use. 3rd ed. Oxford; New York: Oxford University Press; 2003.

27. Lu LNS. Reliability analysis: calculate and compare intra-class correlation coefficients (ICC) in SAS. Proceedings of NESUG (North East SAS Users Group) 2007.

28. Cohen J. A power primer. Psychol Bull. 1992; 112: 155-159.

29. Hays RD, Farivar SS, Liu H. Approaches and recommendations for estimating minimally important differences for healthrelated quality of life measures. COPD. 2005; 2: 63-67.

30. Norman GR, Sloan JA, Wyrwich KW. The truly remarkable universality of half a standard deviation: confirmation through another look. Expert Rev Pharmacoecon Outcomes Res. 2004; 4: 581-585.

31. Chassany $O$, Sagnier $P$, Marquis $P$, Fullerton S, Aaronson N, Group FtERIoQoLA. Patient- Reported Outcomes: The Example of Health-Related Quality of Life- A European Guidance Document for the Improved Integration of HealthRelated Quality of Life Assessment in the Drug Regulatory Process. Drug Inf J. 2002; 36: 209-238.

32. Wyrwich KW, Bullinger M, Aaronson N, et al. Estimating clinically significant differences in quality of life outcomes. Qual Life Res. 2005; 14: 285-295.

33. Bureau USC. Population estimates, Vintage 2011: National Tables (Annual Population Estimates). 2011.

34. Wyrwich KW, Wolinsky FD. Identifying meaningful intra-individual change standards for health related quality of life measures. J Eval Clin Pract. 2000; 6: 39-49. 